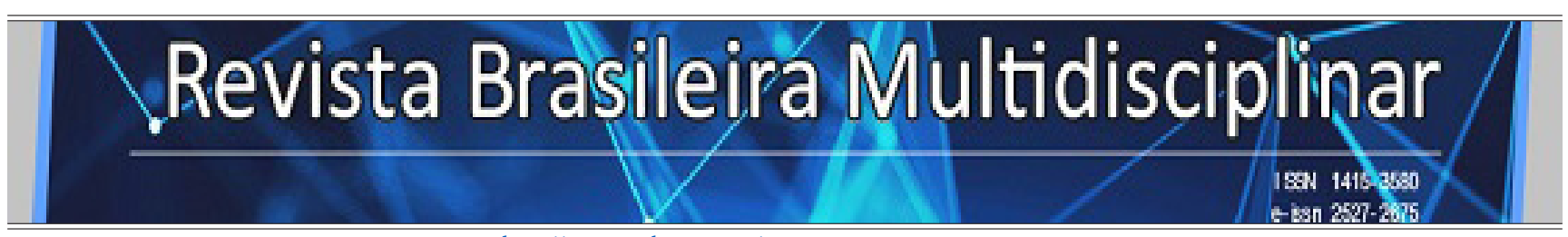

http://revistarebram.com/index.php/revistauniara

\title{
Atividade antifúngica do alho (Allium SATIVUm) Sobre CANDida Albincans
}

\author{
Gabriela Maria Caetano*; Giovana Aparecida Garcia*; Tauana Brizolari Gonçalves*; Juliana Leal Monteiro da Silva**. \\ * Graduanda do curso de Biomedicina da Universidade de Araraquara-UNIARA. \\ ** Doutora em Análise Clínicas pela Unesp-Araraquara-SP. Docente da disciplina de Micologia clínica do centro Universitário de Araraquara.
}

*Autor para correspondência e-mail: julemonte@gmail.com

\section{Palavras-Chave}

\section{Candida Albicans \\ Antifúngico \\ Alho}

\section{KEYWORDS}

Candida Albicans

Antifungal

Garlic

\section{RESUMo}

A Candidíase é uma das micoses oportunistas mais comuns da atualidade, devido a sua alta frequência em acometer pessoas imunologicamente comprometidas. Candida albicans é a principal espécie envolvida nas infecções, causando cerca de $60 \%$ das manifestações clínicas, que podem variar desde uma infecção localizada de mucosas, até uma doença disseminada, potencialmente fatal. O uso excessivo de fármacos convencionais para o tratamento dessa doença, propicia o surgimento de leveduras resistentes sendo assim, há necessidade de descobrir tratamentos alternativos que sejam eficazes contra o fungo e minimizem os efeitos colaterais. O presente estudo teve como objetivo avaliar a atividade antifúngica "in vitro" do alho, sobre amostra de Candida albicans (ATCC 90028), através de técnica de difusão em ágar e através de análises morfológicas. Foram testadas para isso a ação do alho cortado em lascas, um extrato concentrado de alho e o extrato embebido em papel filtro. Pela técnica de difusão em ágar, todas as variáveis testadas tiveram efeito inibitório sobre a C. albicans, quando comparados com o controle utilizando apenas salina. Com relação aos estudos morfológicos, quando acrescentado o extrato de alho no meio ágar fubá, não houve formação de clamidósporos terminais pela levedura, e quando o extrato foi incubado com soro para induzir a formação de tubos germinativos, também teve efeito inibitório, além de ter ação fungicida quando semeado em ágar Sabouraud, após essa incubação. Sendo assim, o alho (Allium sattivum) teve um efeito antifúngico em todos os testes realizados, inibindo o crescimento e filamentação de Candida albicans.

\section{ANTIFUNGAL ACTIVITY OF GARLIC (ALLIUM SATIVUM) ABOUT CANDIDA ALBICANS}

Candidiasis is one of the most common opportunistic mycoses nowadays due to its high frequency in affecting immunologically compromised individuals. Candida albicans is the main species involved in infections, causing about $60 \%$ of clinical manifestations, extending from localized mucosal infection to a potentially fatal widespread disease. The excessive use of candidiasis conventional drugs causes the emergence of resistant yeasts and thus, there is a need to discover effectives alternative treatments against the fungus and minimize the side effects. The objective of the present study was to evaluate the antifungal in vitro activity of garlic on Candida albicans (ATCC 90028) by agar diffusion technique and morphological analysis. The action of the sliced garlic cuts, a concentrated garlic extract and the extract soaked in filter paper were tested. Agar diffusion technique shows that all variables have an inhibitory effect on C. albicans growth, when compared to the saline control. Regarding the morphological studies, when the garlic extract was added in the corn meal agar, there was no formation of terminal chlamydospores by the yeast, and when the extract was incubated with serum to induce the formation of germ tubes. It also had an inhibitory effect, besides showing fungicidal action when sown on Sabouraud agar after this incubation. Thus, garlic (Allium sattivum) had an antifungal effect in all the tests performed, inhibiting the growth and filamentation of Candida albicans. 


\section{INTRODUÇÃo}

Candidíase é uma micose oportunista causada por leveduras do gênero Candida, que apresenta variadas manifestações clínicas, podendo causar desde uma infecção localizada de mucosas até uma doença disseminada potencialmente fatal. Pode acometer vários locais anatômicos, e é causada pelo crescimento excessivo da levedura, sendo a Candida albicans a espécie mais comum, estando presente em $60 \%$ dos isolados clínicos, além de outras espécies como C. parapsilosis, C. tropicalis, C. krusei, entre outras (PEIXOTO et al., 2014; BARBEDO; SGARBI, 2010; FREIRE et al., 2016).

A espécie albicans apresenta distintas morfologias, sendo sua fase unicelular leveduriforme capaz de se reproduzir assexuadamente por brotamento, podendo formar hifas verdadeiras e pseudo-hifas, que são estruturas envolvidas na patogenicidade da levedura quando ocorre variação de temperatura e $\mathrm{pH}$ (SUDBERY et al., 2004). Nessa espécie pode ocorrer a formação de clamidósporos, que são estruturas de resistência, ajudando na diferenciação das espécies (WHITEWAY; BACHEWICH, 2007). É a espécie com maior diversidade de fatores de virulência descobertos, por isso a que se tem maior conhecimento patogênico (FREIRE et al., 2016).

Sabe-se que cerca de 20 a 80\% da população adulta saudável possui espécies de Candida no trato gastrointestinal, e em mulheres, cerca de 20 a 30\% apresentam colonização vaginal por esse grupo de leveduras (COLOMBO; GUIMARÃES, 2003). São componentes da microbiota, sendo encontradas na pele e mucosas, e esta presença acredita-se que está ligada à passagem do bebê pela cavidade vaginal no momento do parto ou durante o procedimento cirúrgico. Estas leveduras podem ser encontradas no recém-nascido em sua boca e trato gastrointestinal. Apesar de serem considerados fungos oportunistas, em condições normais e em organismos sadios, sua presença não é patogênica. Porém, a situação se altera, quando o organismo do hospedeiro sofre modificações e se torna suscetível, favorecendo a infecção pela levedura, e consequentes manifestações clínicas (ALANGADEN, 2011; RIBEIRO et al., 2004).

Vários fatores contribuem para essas infecções, entre eles, o rompimento de barreiras cutânea e mucosa, disfunção dos neutrófilos, defeito na imunidade mediada por células, desordens metabólicas, exposição direta aos fungos, extremos de idade (recém-nascidos e idosos), alterações hormonais, desnutrição aguda, longo tratamento com antibióticos, quimioterapia, transplantes, resistência a antifúngicos, entre outros (GIOLO; SVIDZINSKI, 2010; FREIRE et al., 2016).

Como forma mais comum temos a candidíase mucocutânea, acometendo cavidade oral e vaginal. A candidíase cutânea abrange áreas úmidas do corpo como espaços interdigitais, regiões das mamas, axilas, pregas das virilhas e debaixo das unhas (PEIXOTO et al., 2014).

A candidíase vulvovaginal é uma das doenças fúngicas mais frequentes dentro da esfera genital. Estima-se que três quartos da população feminina mundial manifeste a doença em alguma ocasião de suas vidas, e em muitas delas, a doença é recorrente. Os principais fatores de predisposição para esse tipo de candidíase são: alto teor de glicogênio, a gravidez, a antibioticoterapia, diabetes, contraceptivos orais, terapia de reposição estrogênica, imunossupressores, tipo de vestimenta íntima. As leveduras do gênero Candida, especialmente C. albicans, fazem parte da microbiota normal da vagina de algumas mulheres, sendo assim, em algumas circunstâncias, como o desequilíbrio do $\mathrm{pH}$ por alterações hormonais, fazem com que a população desta levedura aumente desencadeando uma vaginite irritante, com corrimento, prurido, que pode ser acompanhada por uretrite e disúria, muitas vezes simulando uma infecção do trato urinário (TOZZO; GRAZZIOTIN, 2012; FONSECA et al., 2014;; FREIRE et al., 2016). Em um estudo desenvolvido na Universidade Federal de São Paulo (UNIFESP), foram avaliadas 179 pacientes com suspeita clínica de vaginite fúngica, com idades entre 18 e 65 anos e as espécies isoladas foram: $C$. albicans (70\%), C. glabrata (20\%), C. tropicalis (7,5\%) e C. guilliermondii (2,5\%) (BOATTO et al., 2007).

As leveduras do gênero Candida sp. também são comuns como comensais na cavidade bucal, e quando ocorrem problemas relacionados a imunidade do hospedeiro, as infecções se desenvolvem. Chaves e 
colaboradores (2013) realizaram um estudo para determinar a prevalência de leveduras deste gênero na cavidade bucal de pacientes transplantados renais e observaram que cerca de 70 cepas foram isoladas de 111 receptores de transplante, e a espécie mais encontrada foi a Candida albicans (82,86\%).

$\mathrm{Na}$ candidose, ou estomatite induzida por prótese, a Candida albicans atua como o patógeno mais importante e mais virulento. A prevalência da candidose situa-se entre 11 e $67 \%$ dos usuários de próteses dentárias e removíveis (SILVA, 2005). Gasparetto et al. (2005) observaram que a espécie predominante é a Candida albicans constituindo de 60 a 90\% do total dos isolados da cavidade oral seguido por Candida tropicalis e Candida glabrata. A associação da Candida albicans como principal patógeno está diretamente relacionada à sua eficiência em aderir e colonizar as superfícies de próteses dentárias e também das lesões causadas pelas próprias próteses dentárias.

Thomas et al. (2017), realizaram um estudo com 45 crianças com idades variando entre 4 e 6 anos, que possuíam cáries, e constataram a eficácia do uso do alho quando incorporado na solução de enxague bucal, comparando ao grupo controle.

A Candidíase sistêmica é a forma clínica mais preocupante pois vem aumentando incontrolavelmente devido ao grande número de pacientes imunodeprimidos como principais alvos dessas infecções (GIOLO; SVIDZINSKI, 2010). O principal meio de transmissão é por via endógena, em que as espécies de Candida que fazem parte da microbiota de vários sítios anatômicos, sob condições de debilidade do hospedeiro, se comportam como patógenos oportunistas, disseminando-se por vários órgãos. Outro mecanismo de infecção, não menos importante e considerável é por via exógena, que acontece principalmente por meios das mãos de profissionais da saúde, ou através de materiais médico-hospitalares contaminados pelo fungo, não higienizados adequadamente, como catéteres, sondas, soluções intravenosas (GIOLO; SVIDZINSKI, 2010).

Uma preocupação que vem crescendo na área da microbiologia é o aumento da resistência dos microrganismos aos fármacos antifúngicos. E essa resistência é um problema grave de saúde porque sua ocorrência leva a surtos de infecções que podem resultar na morte do paciente. O uso de antifúngicos de maneira profilática nos pacientes de maior risco vem alterando o perfil de sensibilidade das leveduras. O antifúngico mais utilizado é o fluconazol, e ele é responsável pela diminuição das infecções por C. albicans por elas serem mais sensíveis a ele, e também pelo aumento das infecções por espécies não albicans, como a C. glabrata e C. krusei que apresentam resistência ao antifúngico (COLOMBO et al., 2006; TALARMIN et al., 2009).

As espécies C. albicans, C. tropicalis e C. parapsilosis tem boa suscetibilidade aos antifúngicos polienos, fluocitosina, azólicos e equinocandinas. A C. glabrata possui uma baixa sensibilidade aos antifúngicos fluconazol e anfotericina $\mathrm{B}$ e é mais sensível aos antifúngicos equinocandinas, voriconazol e posaconazol. Já a C. krusei apresenta resistência natural ao fluconazol, apresentando uma sensibilidade menor à anfotericina B e uma sensibilidade maior aos azólicos e as equinocandinas (DODDS ASHLEY et al., 2006; ODDS et al., 2003).

Estudos mostram um crescente aumento de infecções causadas por espécies não albicans, e estas cada vez mais apresentam resistência aos antifúngicos, sendo seu uso prolongado responsável por alterar o perfil de sensibilidade das cepas. O número crescente de espécies resistentes aos antifúngicos faz com que sejam necessários estudos epidemiológicos para que essas alterações sofridas pelas espécies possam ser monitoradas, atualizando os padrões de suscetibilidade (MIMÍCA et al., 2009).

Apesar dos antibióticos sintéticos serem fundamentais para o tratamento da maioria das infecções, pode ser que não sirvam para todos os tipos de leveduras, podendo trazer reações adversas e com o tempo apresentar resistência (FONSECA et al., 2014). É crescente o número de infecções por Candida sp resistentes a antifúngicos, principalmente no ambiente hospitalar, tendo elevado a taxa de insucesso na terapêutica contra essa infecção, aumentando a morbidade e mortalidade dos pacientes (FREIRE et 
al., 2016).

A busca por produtos naturais que apresentem uma ação antifúngica eficiente tem se mostrado uma alternativa necessária. Vários produtos naturais a base de alecrim, barbatimão, alho, bardana, gengibre, capim cidreira, já tiveram suas atividades antimicrobianas avaliadas e mostram-se efetivos no controle biológico de microrganismos (CAVALCANTI et al., 2011).

No Brasil, o uso de plantas medicinais é baseada na prática indígena e influenciada pelas culturas africana e portuguesa, sendo assim, o governo estimula o uso dos recursos naturais para a promoção da saúde através de tecnologias eficazes, visando a integração do ser humano com o meio ambiente (MILANI et al., 2016).

C. albicans é a principal levedura isolada em infecções nosocomiais, e o principal agente de fungemia no mundo. A sensibilidade desse agente a antifúngicos tem sido extensivamente estudada no Brasil e no mundo. A utilização de plantas medicinais pode ser uma alternativa terapêutica bastante útil devido a sua eficácia, baixo custo operacional, aliada a relativa facilidade para a aquisição destas pela população e compatibilidade com a cultura regional (FREIRE et al., 2016). Extratos vegetais e óleos essenciais têm sido fonte de várias pesquisas que validam sua eficácia (AQIL et al., 2010; CASTANO et al., 2011; SOUZA et al., 2007).

Atualmente uma das opções para o controle dos fungos é o uso de extratos obtidos de uma gama de espécies botânicas, que promovem a inibição dos fitopatógenos de natureza fúngica. Vários estudos já foram realizados e demonstraram a eficácia do alho no combate e profilaxia de infecções fúngicas (RODRIGUES et al., 2009; SANTOS et al., 2010; DALIRSANI et al., 2011; FONSECA et al., 2014; MILANI et al., 2016).

Alguns estudos compararam o efeito antimicrobiano do alho com penicilina, estreptomicina e outros antibióticos, e os resultados comprovaram o efeito inibidor do crescimento de algumas bactérias até então resistentes a um ou mais antibióticos (RODRIGUES et al., 2009).

Allium sativum é uma planta herbácea, caracterizada por um bulbo (cabeça) dividido em dentes (bulbilhos). Atualmente já foram identificados 30 componentes presentes no alho com efeito terapêutico, tendo vários compostos de organoenxofre como oligossacarídeos, flavonóides e selênio, dentre o mais notável, a alicina que possui ação antiviral, antifúngica e antibiótica, possui também um considerável teor de selênio agindo como antioxidante. Alguns compostos sulfurados presentes no alho possuem atividade hipotensora, hipoglicemiante, hipocolesterolêmica e antiagregante plaquetária, reduzindo o risco de doenças cardiovasculares. As demais substâncias encontradas no alho possuem atividade imunoestimulatória e antineoplásica. O componente ativo do alho com atividade antifúngica é o ajoene, formado a partir da alicina e da enzima alinase. Embora as propriedades antifúngicas do ajoene estejam bem documentadas, os mecanismos exatos de atuação sobre a célula fúngica não são claros, supõe-se que esse composto interfira na parede celular da levedura, alterando sua função (APOLINÁRIO et al., 2008; FONSECA et al., 2014; BURIAN et al., 2017).

Diante das dificuldades com relação ao tratamento de infecções por leveduras do gênero Candida, a pesquisa foi realizada para testar a atividade do alho, um alimento muito utilizado na culinária, sobre Candida albicans espécie que geralmente acomete regiões de mucosa oral e vaginal, visando minimizar e prevenir a infecção, sem o uso de medicamentos que poderiam causar efeitos colaterais e resistência a longo prazo.

\section{Oвjetivo}

Avaliar a atividade antifúngica "in vitro" do alho, sobre amostra de Candida albicans (ATCC 90028), através de técnica de difusão em ágar e através de análises morfológicas (microfilamentação em ágar fubá+tween-80 e prova do tubo germinativo). 


\section{Metodologia}

O trabalho foi realizado no Laboratório de Micologia Clínica da Universidade de Araraquara-UNIARA. Foi utilizada amostra de Candida albicans (ATCC 90028), mantida em micoteca e o alho brasileiro, obtido em supermercado. Para obtenção do extrato bruto, os bulbilhos do alho (aproximadamente 10), foram prensados com auxílio de um espremedor, e a massa obtida foi colocada em um almofariz e macerada com auxílio de um pistilo. Gaze estéril foi utilizada para espremer a massa dentro de um béquer, para obtenção do extrato bruto.

Foi testada a atividade antifúngica do alho (Allium sativum) sobre a Candida albicans, através do teste de Difusão em ágar, microfilamentação em ágar fubá + tween-80 e prova de tubo germinativo. Também foi testada a viabilidade da levedura em ágar Sabouraud após ficar em contato com o alho por 2 horas. Todos os testes foram feitos em triplicata.

Foi utilizado como controle positivo de crescimento, solução salina estéril e como controle negativo suspensão comercial de nistatina: $100.000 \mathrm{UI} / \mathrm{ml}$.

\section{Difusão em Ágar}

\section{Preparo do meio de Cultura}

Foi preparado ágar Sabouraud-dextrose e distribuído em placas grandes $(60 \mathrm{ml})$ esterilizadas. As placas foram deixadas em estufa bacteriológica por 24 horas a $37^{\circ} \mathrm{C}$ para controle de esterilidade.

\section{Preparo da suspensão da leVedura}

A partir de repique de 24 horas em ágar Sabouraud-dextrose, foi preparada suspensão de Candida albicans (ATCC 90028), correspondente a escala 1,0 de McFarland (3,0 x UFC/ml) em salina estéril.

\section{TÉCNICA de Difusão em ÁGAR}

As placas contendo ágar Sabouraud foram inoculadas com a suspensão da levedura, utilizando Swab estéril, passando uniformemente sobre a superfície do meio. As placas foram mantidas em repouso por aproximadamente 5 minutos em temperatura ambiente, para melhor absorção do inóculo no meio de cultura.

Após essa etapa foram realizados poços na placa utilizando tubo de ensaio $(1 \mathrm{~cm}$ de diâmetro) esterilizado na chama do bico de Bunsen. Foram realizados seis poços em uma das placas para serem inoculados 200 $\mu$ l: duplicata do extrato bruto do alho; controle positivo (solução salina estéril); controle negativo (suspensão de nistatina).

Em outra placa os testes foram feitos com discos esterilizados e embebidos com o extrato, salina e nistatina. Também foi colocado o alho cortado em lascas sobre a superfície do ágar.

As placas foram incubadas a $30^{\circ} \mathrm{C}$ por até 72 horas, em seguida realizada a leitura e verificação da presença ou ausência de halos de inibição.

\section{MiCROFilAMENTAÇÃo EM ÁGAR FUBÁ+ TWEEN -80}

Esta técnica baseia-se no princípio de que leveduras quando incubadas num meio com alta concentração de polissacarídeos e Tween 80, em baixa tensão de oxigênio, apresentam a capacidade de filamentar, formando pseudo-hifas e/ou hifas verdadeiras.

A técnica foi realizada em placa de Petri onde foi colocada uma lâmina de vidro sobre um suporte em U e o meio de cultura (ágar fubá + Tween 80) foi distribuído, formando uma película sobre a lâmina. Após a solidificação do meio, a levedura foi semeada em estrias sobre o meio, cobrindo em seguida com a lamínula e umedecida com água estéril. A placa foi incubada a $25^{\circ} \mathrm{C}$ durante 2 a 3 dias e após esse período foi observada a morfologia ao microscópio, colocando a lâmina sobre este e visualizando em 
aumento de 400X.

A espécie albicans através dessa técnica, forma pseudo-hifas com clamidoconídios globosos e terminais, que são estruturas assexuadas de parede espessa com material lipídico e glicogênio.

Para testar a atividade do alho sobre a filamentação das leveduras, foi adicionada uma gota do extrato bruto e em outro teste uma gota de nistatina ao ágar fubá antes de verter na placa de microcultivo. A levedura foi semeada em seguida e incubada conforme a técnica descrita acima.

\section{Prova do Tubo germinativo}

A prova do tubo germinativo é atualmente aceita como confiável para a identificação de Candida albicans. É um teste que caracteriza rápida e presuntivamente as leveduras do gênero Candida. A presença do tubo germinativo em duas horas é importante para a identificação da espécie albicans, sendo que as outras espécies também podem formá-lo, mas depois desse período. O tubo germinativo não deve ser confundido com pseudo-hifas, pois os tubos não formam constrição no ponto de ligação com a célula filha, enquanto pseudo-hifas podem ser septadas e apresentam constrição.

A técnica foi realizada com alça de platina semeando pequena quantidade de cultura pura e recente da levedura em tubo de ensaio com $0,5 \mathrm{ml}$ de soro humano e incubando a $37^{\circ} \mathrm{C}$ por no máximo 3 horas. Após 2 horas, foi coletada duas alçadas do soro e analisado ao microscópio entre lâmina e lamínula. A Candida albicans é capaz de formar o tubo germinativo em até 3 horas. Para testar a atividade inibitória do alho sobre a formação de pseudo-hifas e tubo germinativo, foi adicionado ao soro 1 gota do extrato bruto de alho e como controle negativo 1 gota da suspensão de nistatina. Foi realizado controle positivo, utilizando apenas o soro para visualização dessas estruturas.

\section{TESTE DE VIABILIDADE}

Após incubação com o soro e montagem em lâmina, foi semeada uma alçada da levedura, em todas as condições testadas, em tubos contendo ágar sabouraud-dextrose e em seguida incubados a $30^{\circ} \mathrm{C}$ por 72 horas. Após esse tempo foi verificado a ausência ou presença de crescimento das leveduras, indicando ou não a ação fungicida do alho e da nistatina, quando comparados ao controle de crescimento (apenas soro).

\section{RESUltados}

Os resultados obtidos demonstraram que houve atuação do alho sobre a amostra de Candida albicans testada.

\section{Técnica de Difusão em Ágar}

Na figura 1 pode-se observar que houve inibição do crescimento de Candida albicans em todos os testes realizados com o alho:

1. Extrato aquoso de alho macerado;

2. Alho cortado em lascas;

3. Discos embebidos no extrato aquoso de alho.

Não houve crescimento de leveduras ao redor do controle negativo utilizando nistatina (4 e 5) e houve crescimento ao redor do controle positivo quando só foi utilizado a solução salina (6 e 7). 
Figura 1 - Técnica de difusão em ágar. 1. Extrato aquoso concentrado de alho em poços; 2. Alho in natura (lascas), 3. Discos de papel embebidos em extrato aquoso de alho; 4. Controle negativo de crescimento (Nistatina) em poços, 5. Discos de papel embebidos em Nistatina (controle negativo); 6. Controle positivo de crescimento (salina) em poços; 7 . Discos de papel embebidos em salina (controle positivo).
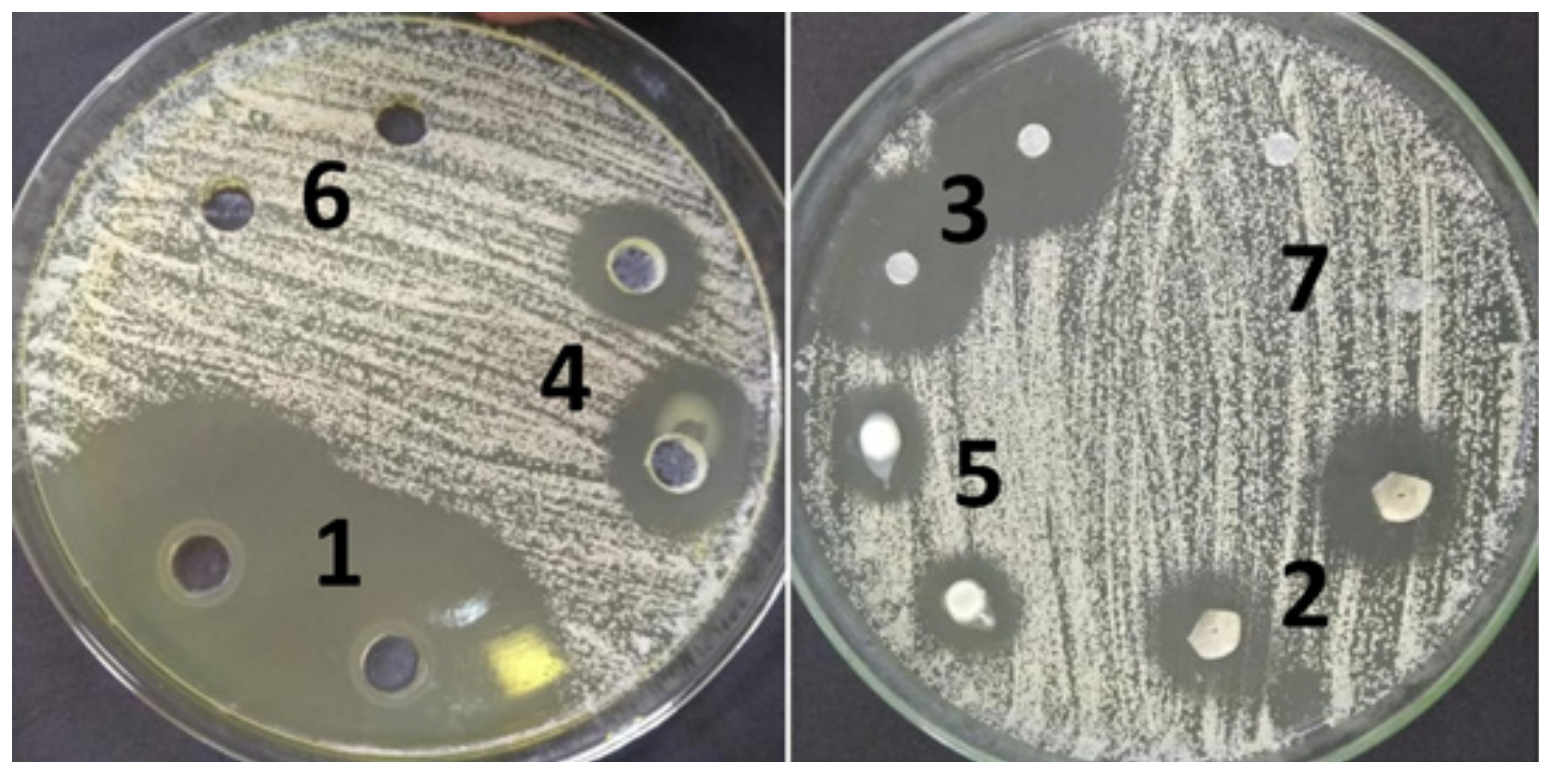

Fonte: Elaborado pelas autoras. 


\section{MiCrofilamentaÇão EM ÁGAR FUBÁ + TWEEN 80}

Candida albicans tem capacidade de filamentar e formar clamidósporos terminais quando cultivada em condições de baixa tensão de oxigênio e alta concentração de polissacarídeos.

Pode-se observar que houve inibição da formação dessas estruturas quando apenas 1 gota do extrato aquoso de alho foi incorporado ao meio de cultivo e depositado em lâmina (figura $2 \mathrm{~A}$ ) e também quando a nistatina foi adicionada (figura $2 \mathrm{~B}$ ) e houve filamentação e formação de clamidósporos terminais quando as leveduras foram cultivadas apenas em Agar fubá + T80 (figura 2C)

Figura 2 - Imagens mostrando a ausência e presença de microfilamentação por Candida albicans (aumento de 400x). A e B: ausência de clamidosporos terminais quando utilizado 1 gota do extrato aquoso do alho e solução de nistatina (controle negativo), respectivamente; C: presença de clamidosporos terminais (controle positivo).

A

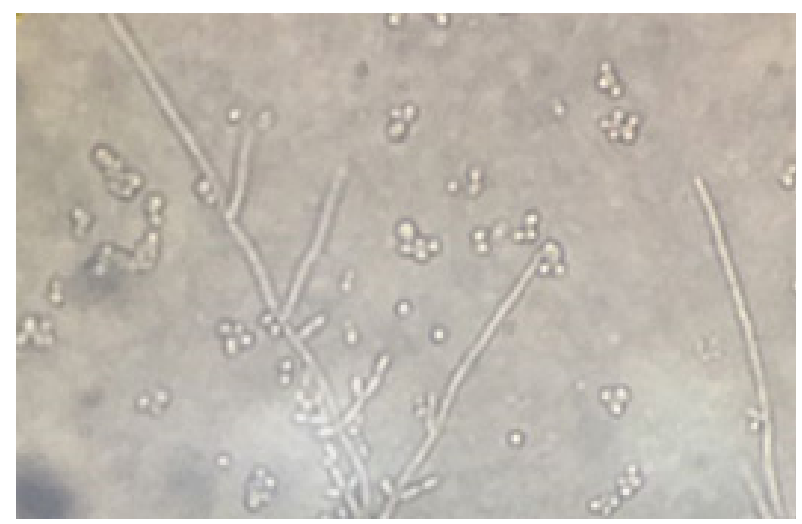

B

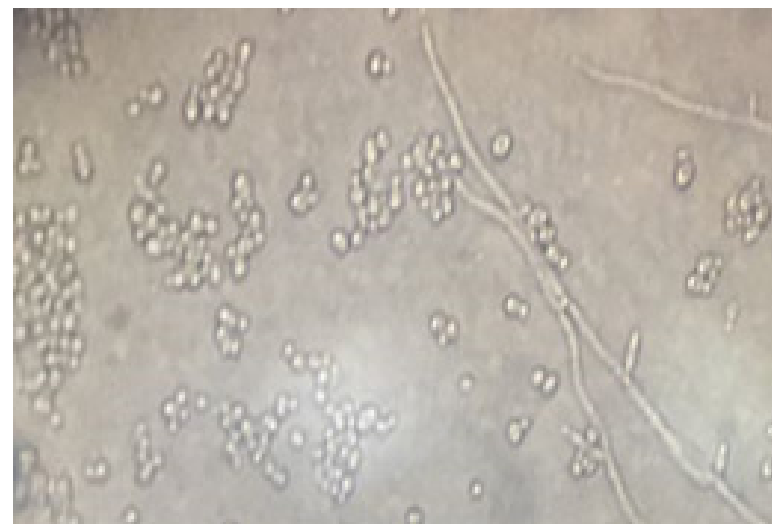

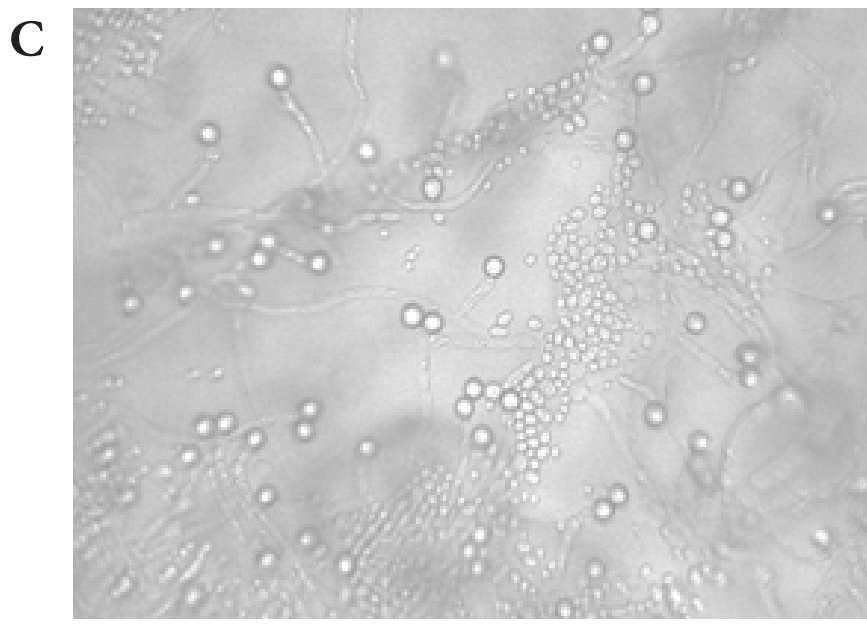

Fonte: Elaborado pelas autoras. 


\section{Prova do Tubo germinativo}

Candida albicans é capaz de formar pseudo-hifas e tubo germinativo rapidamente em condições que mimetizem o nosso organismo. A técnica é realizada com soro humano e incubada por no máximo 3 horas a $37^{\circ} \mathrm{C}$.

Não houve formação de tubo germinativo, nem de pseudo-hifas quando foi adicionado ao soro 1 gota do extrato aquoso do alho (figura 3A) e 1 gota da solução de nistatina (figura 3B). Quando foi utilizado apenas o soro, essas estruturas se formaram em apenas 2 horas (figura 3C).

Figura 3 - Imagens mostrando a inibição e a formação do tubo germinativo com 2 horas de incubação em soro humano (aumento de 400x). A: C. albicans em soro + 1 gota do extrato aquoso de alho; B: C. albicans em soro + Nistatina; C: C. albicans apenas em soro, mostrando a presença do tubo germinativo.
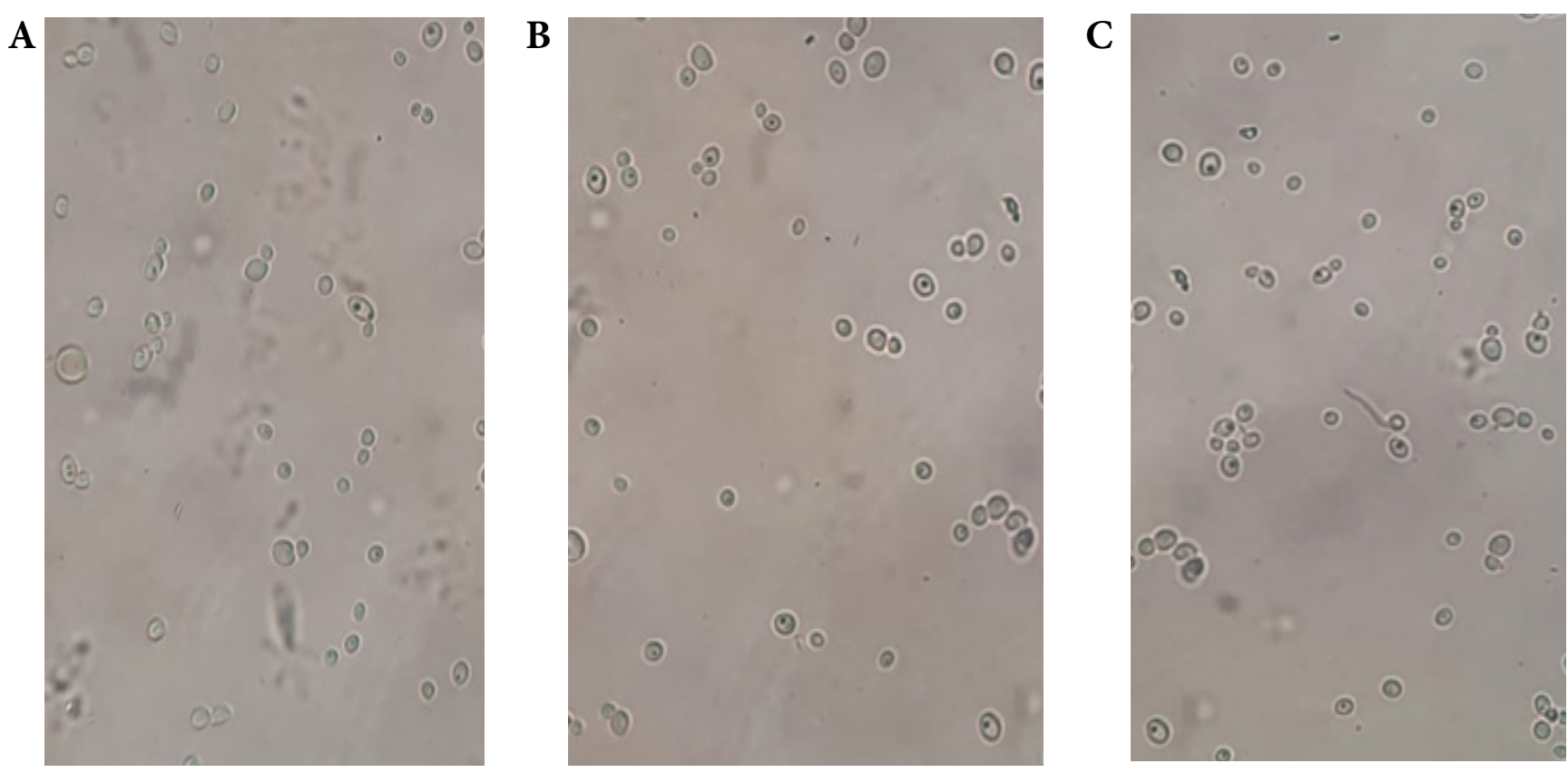

Fonte: Elaborado pelas autoras. 


\section{Teste de viabilidade}

Após 2 horas de incubação da levedura no soro em diferentes condições, foi realizada a semeadura de 1 alçada deste, em ágar Sabouraud e incubado por 72 horas a $30^{\circ} \mathrm{C}$, podendo-se observar que houve crescimento apenas no tubo onde não havia sido colocado o alho e a nistatina, mostrando que além de inibir a formação de qualquer estrutura de filamentação, o alho teve efeito fungicida como a nistatina.

Figura 4 - Semeadura de C. albicans em ágar Sabouraud, após incubação em soro. A: C. albicans + soro + extrato aquoso de alho, mostrando ausência de crescimento; B: C. albicans + soro + nistatina, mostrando ausência de crescimento; C: C. albicans + soro, mostrando crescimento.
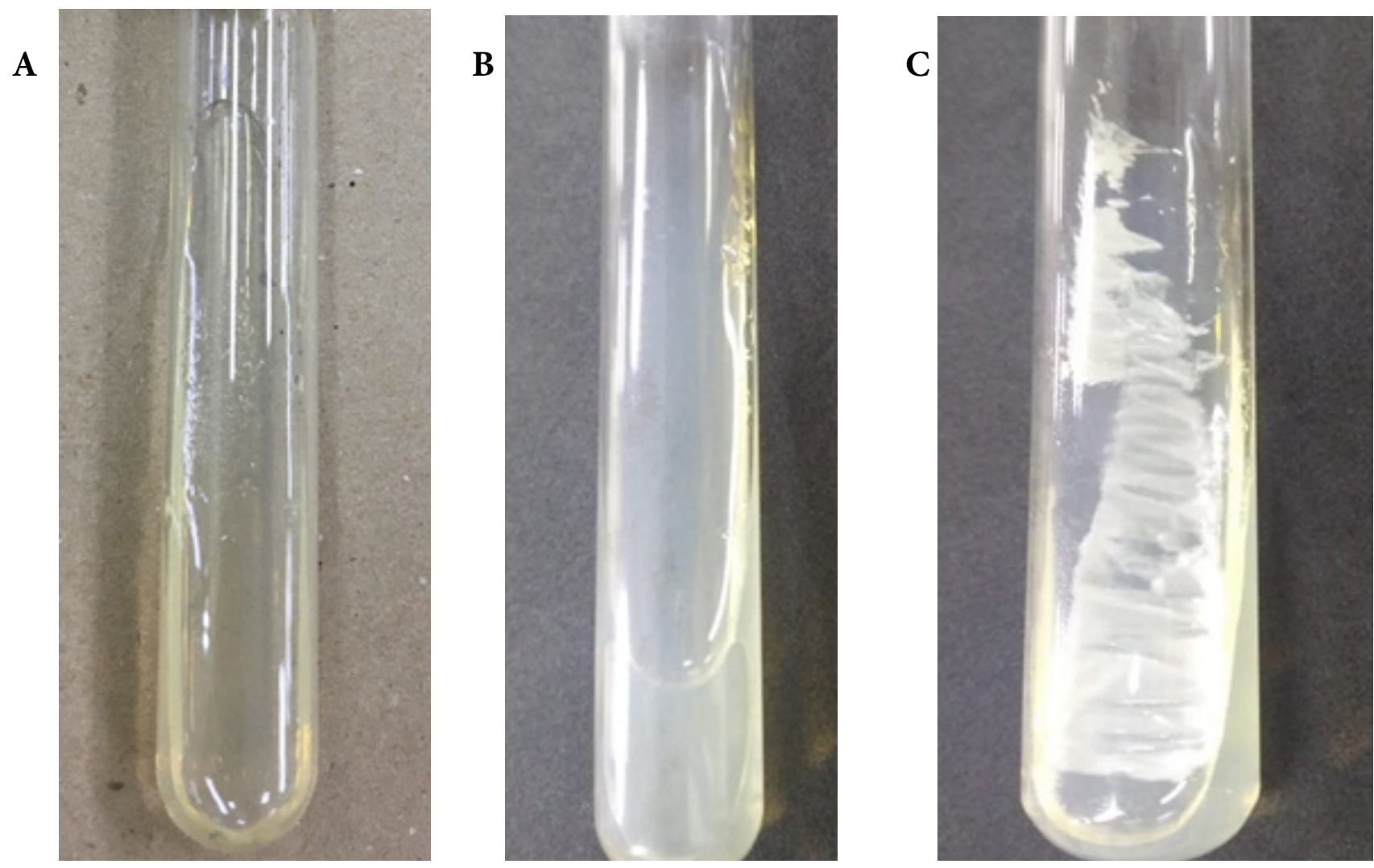

Fonte: Elaborado pelas autoras.

\section{DISCUSSÃo}

As infecções por leveduras do gênero Candida são responsáveis por um número elevado de complicações que ocorrem tanto na área médica quanto odontológica. Sendo assim, a micologia médica ao longo dos anos vem apresentando mudanças significativas com relação ao número crescente de métodos diagnósticos e terapêuticos utilizados em seu tratamento. Os fármacos utilizados algumas vezes apresentam toxicidade causando resistência e recorrência em alguns casos, havendo a necessidade de descobrir tratamentos alternativos que sejam eficazes contra o fungo minimizando os efeitos colaterais.

Atualmente várias plantas e produtos naturais tem sido estudado para avaliação da atividade antifúngica, mas fica difícil a comparação dos resultados já que diferentes apresentações dos produtos são utilizadas (tinturas, extratos, óleo essencial, dentre outros) e diferentes metodologias também são empregadas (FREIRE et al., 2016). 
A Organização Mundial da Saúde (OMS) relata que o comércio de medicamentos fitoterápicos no Brasil gira em torno de $5 \%$ do mercado total, sendo o país com maior diversidade de plantas com potencial terapêutico, incluindo o alho em estudos recentes e confirmação de sua ação contra várias doenças (RODRIGUES et al., 2009; FONSECA et al., 2014; MILANI et al., 2016)

A inserção de um tratamento alternativo e natural para a candidíase é importante, pois desta forma o organismo do paciente, que geralmente está comprometido imunologicamente, não sofre tanto com os tratamentos realizados com drogas sintéticas, por que diminui a agressão ao seu organismo. Os tratamentos alternativos proporcionam até mesmo uma prevenção, pois podem ser inseridos na alimentação do paciente, ou serem aplicados topicamente, diminuindo as chances de resistência causadas pelo microrganismo. Sendo assim, o alho poderia ser uma ótima opção para pacientes sob tratamento que desenvolvem a candidíase cutâneo-mucosa (oral, vaginal, intertriginosa).

Apesar da candidíase oral não ser uma doença mortal, compromete a deglutição, o paladar, causa dor, levando a uma diminuição do apetite em pacientes que já se encontram debilitados. Além disso, essa forma clínica, pode levar a complicações do tipo orofaríngeas, esofágicas e sistêmicas. O tratamento da candidíase oral é simples e geralmente os resultados utilizando antifúngicos tópicos são eficazes, mas em casos de imunossupressão existem altas taxas de recorrência ou recidivas, sendo necessário muitas vezes uma combinação de terapia sistêmica e local (FREIRE et al., 2016)

Pensando nessa problemática, o alho seria uma alternativa extremamente saudável, barata e eficaz para a profilaxia de candidíase oral em pessoas saudáveis e comprometidas imunologicamente. Estudos comprovam a atividade do alho (Allium sativum) sobre cepas de Candida albicans isoladas da cavidade oral de pacientes com doença periodontal e sob radioterapia (RODRIGUES et al., 2009; VENTUROSO et al., 2011).

Além da forma oral, estudos já foram realizados pensando em minimizar os efeitos da candidíase vulvovaginal e infecções bacterianas. Fonseca e colaboradores (2014) testaram o alho intravaginal em nove mulheres sintomáticas e observaram que foram eliminados todos os sintomas causados pela infecção vaginal e apenas uma paciente relatou irritabilidade descontinuando o tratamento. A partir desses resultados de que o alho in natura inibiu o crescimento microbiano, pode ser sugerido para tratamento de infecções vaginais. Alguns profissionais já indicam para mulheres com infecção fúngica e bacteriana, a introdução intravaginal de um bulbilho de alho durante cinco noites e os resultados obtidos na cultura são promissores. A maioria das usuárias não relatam irritação, ardência ou qualquer outro efeito adverso. Outros estudos devem ser realizados para desenvolver formulações mais atrativas, menos irritantes para aplicação tópica do alho na vagina das mulheres e metodologias para avaliação terapêutica.

No presente estudo, foi verificado que a maior inibição de C. albicans, ocorreu quando foi utilizado o extrato macerado de alho, feito a partir dos bulbilhos, quando comparado às lascas aplicadas diretamente sobre a placa semeada e também comparando-se com o antifúngico utilizado (nistatina). Isso pode ter ocorrido pois quando o extrato foi preparado, foi realizada uma maceração dos bulbilhos e rompimento da túnica ou membrana externa do alho, o que possivelmente possibilitou a liberação e ação de seus componentes ativos. O ajoene é o composto ativo do alho com propriedades antifúngicas, sendo formado a partir da mistura da alicina e da enzima alinase, sendo assim, quando o alho é picado ou macerado esses dois compostos se juntam para formar o ajoene, explicando assim a maior ação antifúngica do extrato (BURIAN et al., 2017).

Outros estudos também mostraram uma maior atividade do extrato macerado quando comparado a outras formulações. Rodrigues et al (2009), testaram quatro tipos de extração com o alho e verificaram que a maior inibição de Candida albicans também ocorreu com o extrato macerado. Milani et al (2016) também observaram melhor ação antifúngica do extrato fresco de alho em relação ao antifúngico tes- 
tado, estando de acordo com nossos resultados que mostraram um halo de inibição maior quando foi utilizado o extrato macerado.

Em contrapartida, Fonseca e colaboradores (2014), observaram menor atividade do extrato aquoso sobre Candida albicans, quando comparado ao alho in natura e ao antifúngico utilizado como controle negativo de crescimento (miconazol).

Candida albicans é considerada a espécie mais frequente e mais patogênica, devido ao alto poder de adesão e filamentação, entre outros mecanismos. Por essa razão também testamos nesse estudo, a ação do alho sobre a capacidade de filamentação dessa espécie através da técnica de microfilamentação em lâmina e produção de tubo germinativo. Através dos nossos resultados, pode-se observar que uma pequena quantidade do extrato aquoso de alho adicionado ao meio, foi capaz de inibir a formação dessas estruturas, mostrando uma ação muito eficaz em um dos principais mecanismos de patogenicidade dessa levedura. A formação dessas estruturas micelianas (hifas) aumentam a superfície de contato facilitando a aderência da levedura aos tecidos hospedeiros, com consequente invasão e disseminação do microrganismo no organismo humano (GIOLO; SVIDZINSKI, 2010).

O extrato aquoso de alho também teve ação fungicida sobre a amostra de C. albicans testada, pois a amostra foi semeada em ágar Sabouraud, após tratamento por 2 horas com o alho e não houve crescimento quando comparada a amostra não tratada. O mesmo ocorreu quando a levedura foi incubada com a nistatina.

Apesar do nosso estudo ter sido qualitativo, foi notável a ação do alho sobre a amostra de Candida albicans testada, impedindo a filamentação e causando morte da levedura em poucas horas, porém são necessários outros estudos para confirmar sua ação antifúngica in natura e in vivo para verificar melhor os seus efeitos.

\section{Conclusão}

O alho (Allium sattivum) teve um efeito antifúngico em todos os testes realizados, inibindo o crescimento e filamentação de Candida albicans. O extrato macerado mostrou uma maior atividade, tendo ação fungicida sobre a levedura. Sendo assim, sugere-se seu uso na profilaxia e tratamento de infecções cutâneo-mucosas causadas por essa levedura, visto o baixo custo e grande facilidade de incorporá-lo na alimentação diária como terapia complementar. $\mathrm{O}$ alho merece a atenção da indústria farmacêutica como também deve ter o seu uso popular propagado e orientado de modo que a sociedade como um todo e não só a comunidade acadêmica conheça mais profundamente seus benefícios para a saúde.

\section{Agradecimentos}

Ao Centro Universitário de Araraquara- UNIARA pela disponibilidade do Laboratório para desenvolvimento do trabalho. A todas as pessoas que direta ou diretamente nos ajudaram.

\section{REFERÊNCIAS}

ALANGADEN, G. J. Nosocomial fungal infections: epidemiology, infection control, and prevention. Journal Infectious Disease Clinics of North America, v. 25, p. 201-225, 2011.

AQIL, F. ; ZAHIN, M.; AHMAD, I.; OWAIS, M.; AHMAD KHAN, S.; BANSAL , S. S.; FAROOQ, S. . Antifungal activity of medicinal plant extracts and phytocompounds: a review. Research Gate, 2010.

APOLINÁRIO, A. C.; MONTEIRO, M. M. O.; PACHÚ, C. O Allium sativum. Como agente terapêutico 
para diversas patologias: uma revisão. Revista de Biologia e Farmácia, v. 03, n. 1, 2008.

BARBEDO, L. S.; SGARBI, D. B. Candidíase. DST - Jornal Brasileiro de Doenças Sexualmente Transmissíveis, v. 22, n. 1, p. 22-38, 2010.

BOATTO, H. F.; MORAES, M. S.; MACHADO, A. P.; MACHADO; M; GIRÃOJ. B.C.; FISCHMAN, O. O Correlação entre os resultados laboratoriais e os sinais e sintomas clínicos dos pacientes com candidíase vulvovaginal e relevância dos parceiros sexuais na manutenção da infecção em São Paulo, Brasil. Revista Brasileira de Ginecologia Obstetrícia, v. 29, n. 2, p. 80-84, 2007.

BURIAN, J. P.; SACRAMENTO, L. V. S.; CARLOS, I. Z. Fungal infection control by garlic extracts ( $A l$ lium sativum L.) and modulation of peritoneal macrophages activity in murine model of sporotrichosis. Brazilian Journal of Biology, v. 77, n. 4, p. 848-855, 2017.

CASTAÑO, V. T. ; CORREA-ROYERO, J. ; ZAPATA-LONDOÑO, B.; DURÁN, C.; STANSHENKO, E.; MESA-ARANGO, A. C. Anti-Candida albicans activity, cytotoxicity and interaction with antifungal drugs of essential oils and extracts from aromatic and medicinal plants. Revista Associación Colombiana de Infectología, v. 15, n. 3, p. 160-167, 2011.

CAVAlCANTI, Y. W.; ALMEIDA, L. F. D.; PADILHA, W. W. N. Atividade antifúngica de tinturas de produtos naturais sobre Candida spp. International Journal of Dentistry, v. 10 n. 1, p. 15-19, 2011.

CHAVES, G. M.; DINIZ, M.G, DA SILVA-ROCHA, W.P; DE SOUZA, L.B; GONDIM, L.A; FERREIRA, M.A, Svidzinski TI, Milan EP. Species distribution and virulence factors of Candida sp. Isolated from the oral cavity of kidney transplant recipients in Brazil. Journal Mycopathologia, v. 175, n. 3-4, p. 255-263, 2013.

COLOMBO, A. L.; NUCCI, M.; PARK, B. J.; NOUÉR, S. A.; ARTHINGTON-SKAGGS, B.; DA MATTA, D. A.; WARNOCK, D.; MORGAN, J. Epidemiology of candidemia in Brazil: nationwide sentinel surveillance of candidemia in eleven medical centers. Journal Clinical of Microbiology, v. 44, p. 2816-2823, 2006.

COLOMBO, A. L.; GUIMARÃES, T. Epidemiologia das infecções hematogênicas por Candida sp. Revista da Sociedade de Medicina Tropical, v. 36, n. 05, p. 599-607, 2003.

DALIRSANI, Z.; M. ADIBPOUR; M, AGHAZADE ; M, AMIRCHAGHMAGHI; F, FALAKI; PEGAH, M.M.; HAMZEI, F. M. In vitro Comparison of Inhibitory Activity of 10 Plant Extracts Against Candida albicans. Australian Journal of Basic and Applied Sciences, v. 5, n. 5, p. 930-935, 2011.

DODDS ASHLEY, E.S.; LEWIS, RUSSELL.; LEWIS, J.S.; MARTIN, C.; ANDES, D. Pharmacology of systemic antifungal agents. Journal Clinical Infectious Diseases, v. 43, p. 28-39, 2006.

FONSECA, G. M.; PASSOS, T.C.I; NINAHUAMAN, M.F.M.L.I; CAROCI, A.S.II; COSTA, L.S.I. Avaliação da atividade antimicrobiana do alho (Allium sativum Liliaceae) e de seu extrato aquoso. Revista Brasileira de Plantas Medicinais, v. 16, n. 3, p. 679-684, 2014.

FREIRE, J. C. P.; NÓBREGA, M. T. C.; OLIVEIRA-JÚNIOR, J. K. DE; FREIRE, S. C. P.; RIBEIRO, E. D.; 
LIMA, E. DE O. Atividade antifúngica de fitoterápicos sobre espécies de Candida: uma revisão de literatura. Revista Archives of Health Investigations, v. 5, n. 6, p. 307-310, 2016.

GASPARETTO, A.; NEGRI, M. F. N.; PAULA, C. R.; SVIDZINSKI, T. I. Produção de biofilme por leveduras isoladas de cavidade bucal de usuários de prótese dentária. Revista Acta Scientiarum Health Sciences, v. 27, n. 1, p. 37-40, 2005.

GIOLO, M. P.; SVIDZINSKI, T. I. E. Fisiopatogenia, epidemiologia e diagnóstico laboratorial da candidemia. Jornal Brasileiro de Patologia e Medicina Laboratorial, v. 46, n. 3, p. 225-234, 2010.

MILANI, H. L. D; TEIXEIRA, A. X.; SOUSA, E.; ABREU, V.; NINAHUAMAN, M. F. M. Avaliação da atividade antimicrobiana in vitro do alho (Allium sativum) in natura. Revista Acta Scientiae Biological Research, v. 1, n. 1, p. 47-58, 2016.

MIMICA, L. M. J. Diagnóstico de infecção por Candida: avaliação de testes de identificação de espécies e caracterização do perfil de suscetibilidade. Jornal Brasileiro de Patologia e Medicina Laboratorial, v. 45 , n. 1, p. 17-23, 2009.

ODDS, F. C.; BROWN, A. J.; GOW, N. A. Antifungal agents: mechanisms of action. Journal Trends in Microbiology, v. 11, n. 6, p. 272-279, 2003.

PEIXOTO, J. V.; ROCHA, M. G. ; NASCIMENTO, R. T. L. ; MOREIRA, V. V. ; KASHIWABARA, T. G. B. Candidíase- Uma revisão de literatura, Brazilian Journal of Surgery and Clinical Research - BJSCR, v. 8, n. 2, p. 75-82, 2014.

SILVA, A. K. F. ; LISBOA, J. E. S.; BARBOSA, M. P. C. S.; LIMA, A. F. Aspectos das leveduras de Candida vinculadas as infecções nosocomiais. Revista Newslab, ed. 64, p. 106-128, 2004.

RODRIGUES, M. M. ; SANTOS, S. S. F.; CLARO, C. A.A.; SCHERMA, A.P. Avaliação in vitro da atividade antifúngica do Allium sativum sobre cepas e Candida albicans isoladas de cavidade bucal. Revista de Periodontia, v. 19, n. 2, p. 124-132, 2009.

SANTOS, M. B.; ALMEIDA, M.A; SANTOS, C.R.S; S SANT'ANNA, H.L; SANTOS, O.S.N ; SILVA, F; MARTINS, G.N. Efeito inibitório in vitro de extrato vegetal de Allium sativum sobre Aspergillus níger Tiegh. Revista Brasileira de Plantas Medicinais, v. 12, n. 1, p. 13-17, 2010.

SILVA, W. J. Efeito da nistatina, fluconazol e do extrato etanólico de própolis de Apis mellifera sobre propriedades de superfície de resina acrílica. Dissertação - Universidade Estadual de Campinas - Faculdade de Odontologia, Piracicaba. 90 folhas - 2005.

SOUZA, A. E. F.; ARAÚJO, E.; NASCIMENTO, L. C. Atividade antifúngica de extratos de alho e capim-santo sobre o desenvolvimento de Fusarium proliferatum isolado de grão de milho. Revista Fitopatologia Brasileira, v. 32, n. 6, p. 465-471, 2007.

SUDBERY, P.; GOW, N.; BERMAN, J. The distinct morfhogenic states of Candida albicans. Trends Microbiology, v. 12, n.7, p. 317-324, 2004. 
TAlARMIN, J.; P., BOUTOILlE, D.; TATTEVIN, P.; ABGUEGUEN, P.; ANSART, S.; ROBLOT, F.; RAFFI, F. Candida endocarditis: role of new antifungal agents. Mycoses, v. 52, p. 60-66, 2009.

THOMAS, A.; THAKUR, S.; HABIB, R. Comparison of Antimicrobial Efficacy of Green Tea, Garlic with Lime, and Sodium Fluoride Mouth Rinses against Streptococcus mutans, Lactobacilli species, and Candida albicans in Children: A Randomized Double-blind Controlled Clinical Trial. International Journal of Clinical Pediatric Dentistry, v. 10, n. 3, p. 234-239, 2017.

TOZZO, A. B.; GRAZZIOTION, N. A. Candidíase vulvovaginal (Vulvovaginal Candidiasis). Revista Perspectiva. v.36, n.133, p.53-62, 2012.

VENTUROSO, L. R; BACCHI, L.M.A.; GAVASSONI, W.L.; PONTIM, B.C.A.; CONUS, A. Influência de diferentes metodologias de esterilização sobre a atividade antifúngica de extratos aquosos de plantas medicinais. Revista Brasileira de Plantas Medicinais, v. 12, n. 4, p. 499-505, 2010.

WHITEWAY, M.; BACHEWICH, C. Morfogênese em Candida albicans. Annual Reviews, v. 61, p. 529553, 2007. 